\title{
Improvement of Globalization Themes Learning Results in The Science Content Through The Blended Learning Learning Model
}

\author{
Anny Rahayu
}

SDN 1 Magelung

anny.rahayu2@gmail.com

\section{Article History}

accepted 14/11/2020

approved $21 / 11 / 2020$

published $26 / 11 / 2020$

\begin{abstract}
The purpose of this study was to improve student learning outcomes in science muple class VI elementary schools with the Blended Learning learning model with online PPT media with Zoom Meet. The research conducted was a Classroom Action Research (PTK) with three cycles, with each cycle consisting of two meetings. The stages of each cycle are planning, implementing, observing and reflecting. Each meeting is carried out a pre test and post test to determine the progress of students. In the first cycle the students who completed after carrying out the post test were $79 \%$. In the second cycle students who completed after carrying out the post test were $88 \%$. In the third cycle students who completed after carrying out the post test were $91 \%$. These results indicate that the Blended Learning learning model can improve student learning outcomes, especially Class VI science muple at SDN 1 Magelung.
\end{abstract}

Keywords: learning outcomes, blended learning, science

\begin{abstract}
Abstrak
Tujuan dari penelitian ini adalah untuk meningkatkan hasil belajar peserta didik pada mupel IPA di sekolah dasar kelas VI dengan model pembelajaran Blended Learning dengan media PPT secara daring dengan Zoom Meet. Penelitian yang dilakukan adalah Penelitian Tindakan Kelas (PTK) sebanyak tiga siklus, dengan setiap siklusnya terdiri dari dua pertemuan. Tahapan setiap siklusnya adalah perencanaan, pelaksanaan, observasi dan refleksi. Setiap pertemuan dilakukan pre test dan post test untuk mengetahui perkembangan peserta didik. Pada siklus I peserta didik yang tuntas setelah melaksanakan post test sebesar $79 \%$. Pada siklus II peserta didik yang tuntas setelah melaksanakan post test sebesar $88 \%$. Pada siklus III peserta didik yang tuntas setelah melaksanakan post test sebesar $91 \%$. Hasil ini menunjukkan bahwa model pembelajaran Blended Learning dapat meningkatkan hasil belajar peserta didik khususnya mupel IPA Kelas VI di SDN 1 Magelung.
\end{abstract}

Kata kunci: hasil belajar, blended learning, IPA $\begin{array}{lr}\text { Social, Humanities, and Education Studies (SHEs): Conference Series } & \text { p-ISSN 2620-9284 } \\ \text { https://jurnal.uns.ac.id/shes } & \text { e-ISSN 2620-9292 }\end{array}$ 


\section{PENDAHULUAN}

Pendidikan merupakan suatu usaha untuk merubah dan menambah pengetahuan, tingkah laku, mengembangkan potensi serta keterampilan ke arah yang lebih baik. Kegiatan belajar mengajar di sekolah pada umumnya cenderung monoton dan tidak menarik, sehingga beberapa pelajaran ditakuti dan dianggap sulit oleh peserta didik khususnya pada muatan pelajaran IPA. Hal ini ditunjukkan oleh beberapa hal, diantaranya adalah kolerasi positif dengan perolehan KKM yang selalu menempati urutan terendah. Selain itu, motivasi anak dalam belajar menjadi rendah dikarenakan model pembelajaran yang tidak menarik. Rendahnya hasil belajar peserta didik ini tidak terlepas dari proses pembelajaran yang dilaksanakan oleh guru, oleh sebab itu perlu adanya upaya untuk meningkatkan hasil belajar peserta didik yang meliputi ranah kognitif, afektif, dan psikomotor.

Di masa pandemi pembelajaran tatap muka di sekolah dilarang diganti dengan pembelajaran dari rumah sesuai dengan Surat Edaran Nomor 4 Tahun 2020 Tentang Pelaksanaan Kebijakan Pada Masa Pandemi Belajar dari Rumah melalui pembelajaran daring/jarak jauh. Masalah yang baru pun muncul, selain bagaimana melaksanakan pembelajaran jarak jauh tetapi juga bagimana cara guru tetap melakukan proses pembelajaran yang baik selama pandemi. Proses pembelajaran yang baik harus disesuaikan dengan karakteristik peserta didik agar peserta didik dapat menangkap materi yang diajarkan dengan baik. Pembelajaran yang dilakukan oleh guru juga harus kreatif dan tidak boleh monoton sehingga peserta didik tidak bosan. Penyampaian materi juga harus bervariasi agar peserta didik terdorong semangatnya sehingga aktif dan terus belajar. Guru tidak hanya berfokus pada penyampaian materinya tetapi juga harus memperhatikan perkembangan peserta didik yang terjadi di dalam proses pembelajaran.

Kasus rendahnya pemahaman peserta didik mengenai materi IPA masih banyak terjadi di SDN 1 Magelung. Hasil belajar IPA pada peserta didik kelas VI masih rendah, hal ini dapat dilihat dari hasil observasi awal dimana hanya terdapat $68 \%$ peserta didik yang sudah dinyatakan tuntas. Rendahnya nilai muatan pelajaran IPA ini mendorong peneliti untuk melakukan Penelitian Tindakan Kelas dengan meningkatkan hasil belajar peserta didik pada muatan pelajaran IPA dengan menggunakan model Pembelajaran Blended Learning.

Menurut Nana Sudjana (2005: 20) hakikat hasil belajar adalah perubahan tingkah laku individu yang mencakup aspek kognitif, afektif, dan psikomotorik. Menurut Nana Sudjana (2005 : 38) hasil belajar yang dicapai peserta didik dipengaruhi oleh dua faktor utama yakni faktor dari dalam diri peserta didik itu dan faktor yang datang dari luar diri peserta didik atau faktor lingkungan. Faktor yang datang dari diri peserta didik terutama kemampuan yang dimilikinya. Faktor kemampuan peserta didik besar sekali pengaruhnya terhadap hasil belajar yang dicapai. Disamping faktor kemampuan yang dimiliki peserta didik, juga ada faktor lain, seperti motivasi belajar, minat dan perhatian, sikap dan kebiasaan belajar, ketekunan, sosial ekonomi, faktor fisik dan psikis.

IPA adalah mata pelajaran yang termasuk ke dalam kelompok muatan pelajaran yang bertujuan untuk mengembangkan kompetensi sikap, pengetahuan dan keterampilan, ketiga aspek tersebut dapat dikembangkan melalui proses pembelajaran IPA yang mempunyai karakteristik ilmiah dan logis melalui proses pengamatan, hal tersebut kembali diperkuat oleh pendapat dari Sujana (2009: 92) menjelaskan bahwa IImu Pengetahuan Alam atau (sains) merupakan hasil kegiatan manusia berupa pengetahuan, gagasan dan konsep yang terorganisasi secara logis dan sistematis tentang alam sekitar, yang diperoleh dari pengalaman melalui serangkaian proses ilmiah seperti: pengamatan, penyelidikan, penyusunan hipotesis yang diikuti dengan pengujian gagasan. 
SHEs: Conference Series 3 (3) (2020) $653-659$

Pada awalnya istilah Blended learning juga dikenal dengan konsep pembelajaran hiprida yang memadukan pembelajaran tatap muka, online dan offline namun akhir ini berubah menjadi blended learning. Blended artinya campuran atau kombinasi sedangkan learning adalah pembelajaran. Pendapat pula dinyatakan oleh Graham bahwasannya blended learning merupakan perpaduan atau kombinasi dari berbagai pembelajaran yaitu mengkombinasikan pembelajaran tatap muka (face to face) dengan konsep pembelajaran tradisional yang sering dilakukan oleh praktisi pendidikan dengan melalui penyampaian materi langsung pada peserta didik dengan pembelajaran online dan offline yang menekankan pada pemanfaatan teknologi.

\section{METODE}

Penelitian ini adalah penelitian tindakan kelas (Classroom Action Research) dengan menerapkan model pembelajaran Blended Learning. Menurut Kurt Lewin dalam Kunandar (2011: 42) penelitian tindakan kelas ini terdiri dari empat tahapan dasar yaitu perencanaan (planning), pelaksanaan (acting), pengamatan (observing) dan refleksi (reflecting). Analisis penelitian ini adalah analisis deskriptif kuantitafif kualitatif dimana dalam penelitian ini selain penyajian hasil berupa data maupun angka peneliti juga menentukan bagaimana cara pengolahan hasil penelitian yakni dengan membuat analisisnya dengan menerapkan model pembelajaran Blended Learning. Penelitian ini dilaksanakan pada peserta didik kelas VI SDN 1 Magelung Tahun Pelajaran 2020/2021 selama tiga siklus secara daring menggunakan aplikasi Zoom Meeting dengan media Audio Visual dan permainan quiz dengan Aplikasi Kahoot. Siklus I dilaksanakan pada tanggal 2 November 2020. Siklus II dilaksanakan pada tanggal 9 November 2020. Siklus III dilaksanakan pada tanggal 20 November 2020. Teknik pengumpulan data yang dilakukan dengan observasi dan tes, baik pre test maupun post test. Observasi meliputi observasi keterlaksanaan model pembelajaran Blended Learning, sikap peserta didik dan keterampilan. Untuk hasil belajar menggunakan tes melalui Google form.

HASIL DAN PEMBAHASAN

Tabel 1: Distribusi Frekuensi Hasil Belajar Ilmu Pengetahuan Alam Pra Siklus

\begin{tabular}{lllll}
\hline Interval & Frekwensi & Prosentase & Predikat & Kategori \\
\hline $87<\mathrm{A} \leq 100$ & 2 & $6 \%$ & $\mathrm{~A}$ & Sangat Baik \\
\hline $76<\mathrm{B} \leq 88$ & 9 & $26 \%$ & $\mathrm{~B}$ & Baik \\
\hline $65<\mathrm{C} \leq 76$ & 12 & $35 \%$ & $\mathrm{C}$ & Cukup \\
\hline $\mathrm{D}<65$ & 11 & $32 \%$ & $\mathrm{D}$ & Perlu Bimbingan \\
\hline Jumlah & 34 & $100 \%$ & & \\
\hline
\end{tabular}

Berdasarkan tabel di atas diketahui bahwa sebanyak 2 orang $(6 \%)$ memperoleh hasil belajar IImu Pengetahuan Alam dalam kategori Sangat Baik, 9 orang (26\%) kategori baik, 12 orang (35\%) kategori cukup, dan 11 orang (32\%) kategori Perlu Bimbingan dengan rata-rata hasil belajar IImu Pengetahuan Alam peserta didik sebesar 67 maka dapat diketahui bahwa secara keseluruhan hasil belajar IImu Pengetahuan Alam peserta didik dalam Penilaian Harian kelas VI SD Negeri 1 Magelung berada pada kategori cukup.

Selengkapnya dapat dilihat dalam grafik batang berikut ini : 
SHEs: Conference Series 3 (3) (2020) 653 - 659

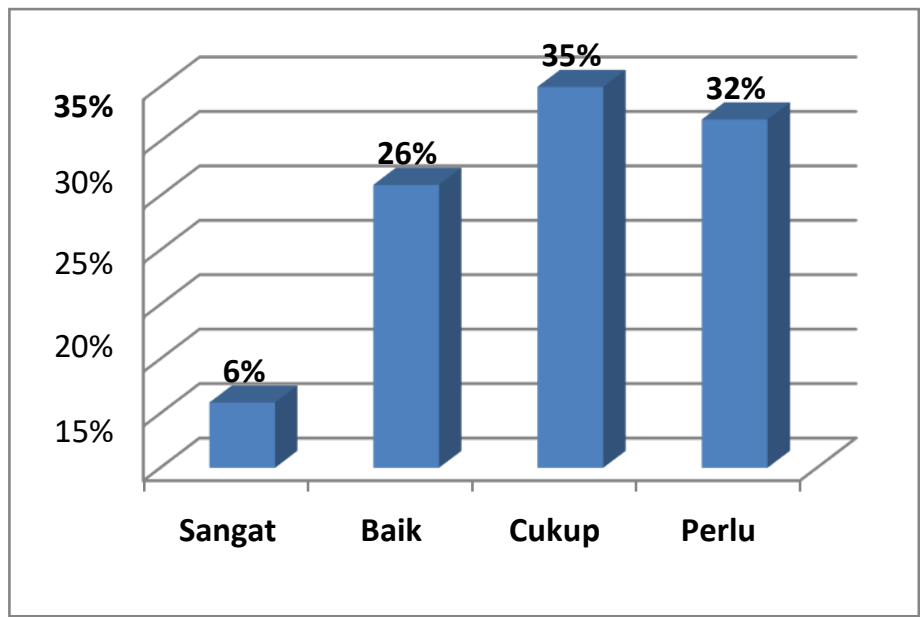

Gambar 1: Grafik Batang Hasil Belajar Ilmu Pengetahuan Alam Pra Siklus

Tabel 2. Distribusi Frekuensi Hasil Belajar IImu Pengetahuan Alam Siklus I

\begin{tabular}{lllll}
\hline Interval & Frekwensi & Prosentase & Predikat & Kategori \\
\hline $87<\mathrm{A} \leq 100$ & 5 & $15 \%$ & $\mathrm{~A}$ & Sangat Baik \\
\hline $76<\mathrm{B} \leq 88$ & 17 & $50 \%$ & $\mathrm{~B}$ & Baik \\
\hline $65<\mathrm{C} \leq 76$ & 5 & $15 \%$ & $\mathrm{C}$ & Cukup \\
\hline $\mathrm{D}<65$ & 7 & $21 \%$ & $\mathrm{D}$ & Perlu Bimbingan \\
\hline Jumlah & 34 & $100 \%$ & & \\
\hline
\end{tabular}

Berdasarkan tabel di atas diketahui bahwa sebanyak 5 orang (15\%) memperoleh hasil belajar IImu Pengetahuan Alam dalam kategori Sangat Baik, 17 orang (50\%) kategori baik, 5 orang (15\%) kategori cukup, dan 7 orang (21\%) kategori kurang dengan rata-rata hasil belajar IImu Pengetahuan Alam peserta didik sebesar 76 maka dapat diketahui bahwa secara keseluruhan hasil belajar IImu Pengetahuan Alam peserta didik dalam Penilaian Harian kelas VI SD Negeri 1 Magelung berada pada kategoribaik.

Selengkapnya dapat dilihat dalam grafik batang berikut ini:

\section{Hasil Belajar IImu Pengetahuan Alam}

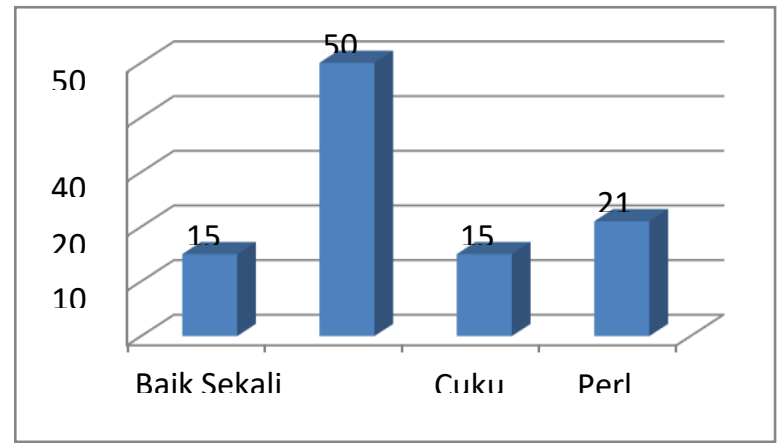

Gambar 2: Grafik Batang Hasil Belajar IImu Pengetahuan Alam Siklus I 
SHEs: Conference Series 3 (3) (2020) 653-659

Tabel 3. Distribusi Frekuensi Hasil Belajar IImu Pengetahuan Alam Siklus II

\begin{tabular}{lllll}
\hline Interval & Frekwensi & Prosentase & Predikat & Kategori \\
\hline $87<\mathrm{A} \leq 100$ & 11 & $32 \%$ & $\mathrm{~A}$ & Sangat Baik \\
\hline $76<\mathrm{B} \leq 88$ & 14 & $41 \%$ & $\mathrm{~B}$ & Baik \\
\hline $65<\mathrm{C} \leq 76$ & 5 & $15 \%$ & $\mathrm{C}$ & Cukup \\
\hline $\mathrm{D}<65$ & 4 & $12 \%$ & $\mathrm{D}$ & Perlu Bimbingan \\
\hline Jumlah & 34 & $100 \%$ & & \\
\hline
\end{tabular}

Berdasarkan tabel di atas diketahui bahwa sebanyak 11 orang (32\%) memperoleh hasil belajar IImu Pengetahuan Alam dalam kategori Sangat Baik, 14 orang (41\%) kategori baik, 5 orang (15\%) kategori cukup, dan 4 orang (12\%) kategori kurang dengan rata-rata hasil belajar IImu Pengetahuan Alam peserta didik sebesar 80 maka dapat diketahui bahwa secara keseluruhan hasil belajar Ilmu Pengetahuan Alam peserta didik dalam Penilaian Harian kelas VI SD Negeri 1 Magelung berada pada kategori baik.

Selengkapnya dapat dilihat dalam grafik batang berikut ini:

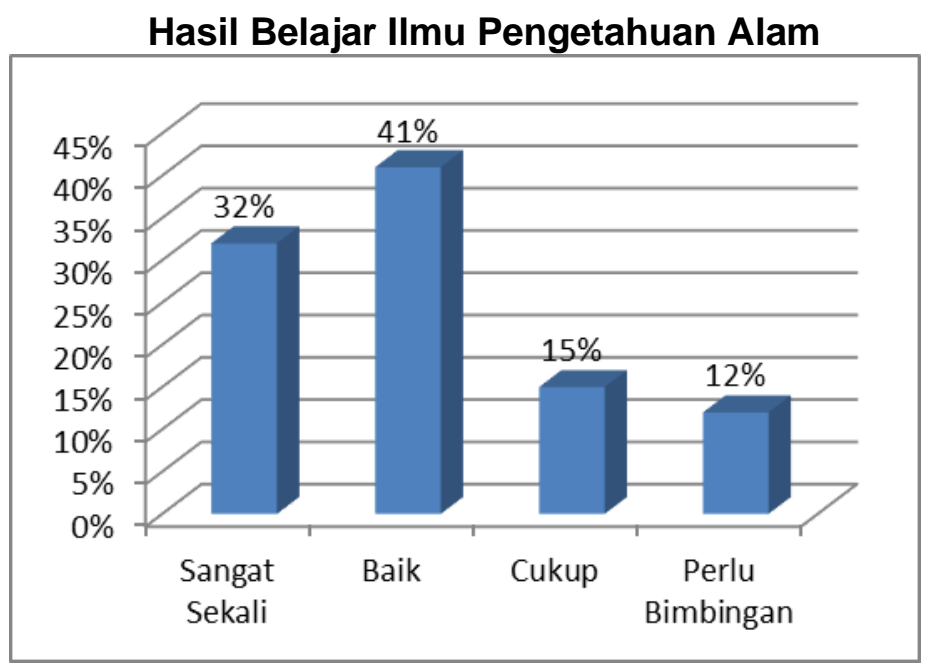

Gambar 3: Grafik Batang Hasil Belajar IImu Pengetahuan Alam Siklus II Tabel 4:

Distribusi FrekuensiHasil Belajar Ilmu Pengetahuan Alam Siklus 3

\begin{tabular}{lllll}
\hline Interval & Frekwensi & Prosentase & Predikat & Kategori \\
\hline $87<\mathrm{A} \leq 100$ & 10 & $29 \%$ & $\mathrm{~A}$ & Sangat Baik \\
\hline $76<\mathrm{B} \leq 88$ & 17 & $50 \%$ & $\mathrm{~B}$ & Baik \\
\hline $65<\mathrm{C} \leq 76$ & 4 & $12 \%$ & $\mathrm{C}$ & Cukup \\
\hline $\mathrm{D}<65$ & 3 & $9 \%$ & $\mathrm{D}$ & Perlu Bimbingan \\
\hline Jumlah & 34 & $100 \%$ & & \\
\hline
\end{tabular}

Berdasarkan tabel di atas diketahui bahwa sebanyak 10 orang (29\%) memperoleh hasil belajar IImu Pengetahuan Alam dalam kategori Sangat Baik, 17 orang $(50 \%)$ kategori baik, 4 orang $(12 \%)$ kategori cukup, dan 3 orang $(9 \%)$ kategori perlu bimbingan dengan rata-rata hasil belajar IImu Pengetahuan Alam peserta didik sebesar 81 maka dapat diketahui bahwa secara keseluruhan hasil belajar IImu Pengetahuan Alam peserta didik dalam Penilaian Harian kelas VI SD Negeri 1 
Magelung berada pada kategori baik.

Selengkapnya dapat dilihat dalam grafik batang berikut ini:

\section{Hasil Belajar IImu Pengetahuan Alam}

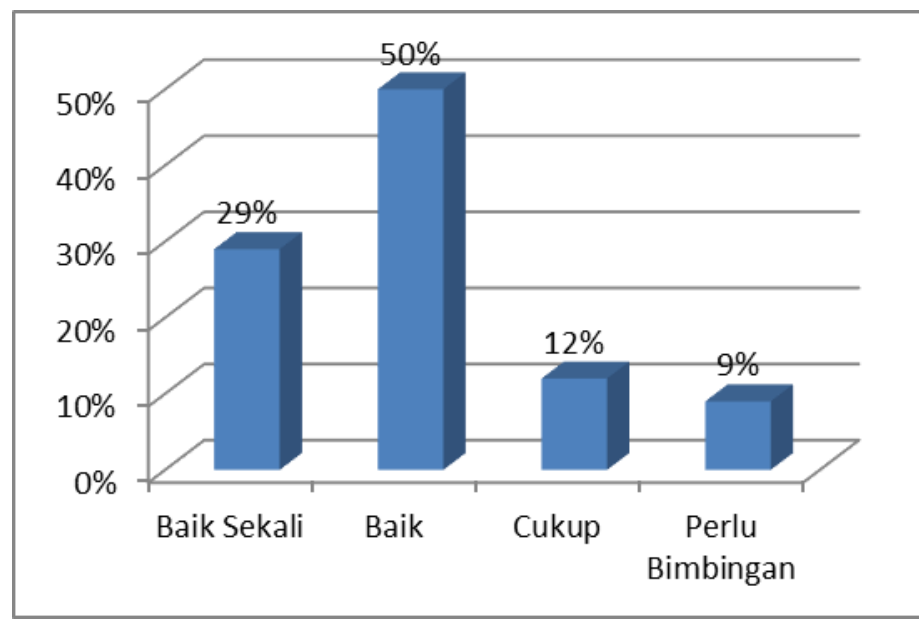

Gambar 4: Grafik Batang Hasil Belajar IImu Pengetahuan Alam Siklus III

Tabel 5 : Perbandingan Hasil Penelitian

\begin{tabular}{llllll}
\hline No & Uraian & Pra Siklus & Siklus I & Siklus II & Siklus III \\
\hline 1. & Hasil Belajar & 67 & 76 & 79 & 81 \\
\hline 2. & Indikator Kerja & $68 \%$ & $79 \%$ & $84 \%$ & $91 \%$ \\
\hline
\end{tabular}

Berdasarkan tabel di atas dapat digambarkan dengan grafik di bawah ini :

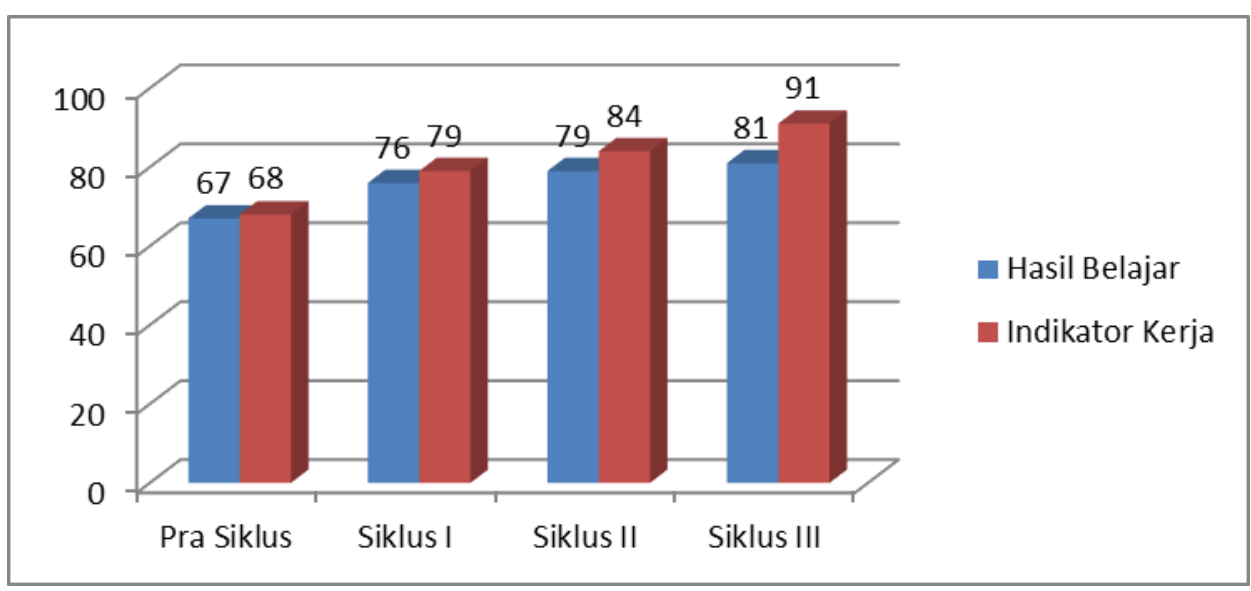

\section{Gambar 5 : Grafik Batang Perbandingan Hasil Penelitian Tiap Siklus}

Perubahan dalam masing-masing peserta didik dan guru dalam proses pembelajaran siklus III, seperti sudah tidak terlihat bingung dikarenakan sudah terbiasa dengan menggunakan media video dan bermain quiz Kahoot. Peserta didik tidak mengobrol lagi saat mengerjakan Lembar Kerja Peserta didik sehingga waktu yang digunakan sangatlah efisien. Selain itu guru yang sudah akrab atau mengetahui sifat masing-masing peserta didik dan mengetahui kemampuan masing-masing peserta didik sehingga dapat mengontrol peserta didik dengan baik dan pembelajaran berjalan dengan baik. Hasil belajar ranah kognitif belajar pada penelitian ini telah memenuhi target dimana pencapaian KKM lebih besar dari yang diharapkan yaitu sebesar $91 \%$ 
dengan skor rata-rata 81. Hal ini membuktikan bahwa materi yang disampaikan dapat dimengerti dan dipahami, fakta tersebut membuktikan bahwa model pembelajaran Blended Learning membantu peserta didik meningkatkan hasil belajar IImu Pengetahuan Alam kelas VI SD Negeri 1 Magelung.

\section{SIMPULAN}

Pembelajaran Tema Globalisasi pada muatan IImu Pengetahuan Alam melalui model Pembelajaran Blended Learning menggunakan media audio visual di kelas $\mathrm{VI}$ SD Negeri 1 Magelung meningkatkan hasil belajar peserta didik. Hal ini ditunjukkan dengan perolehan data hasil belajar peserta didik pada siklus I nilai rata-rata hasil belajar peserta didik adalah 76 dengan persentase ketuntasan belajar klasikal sebesar $79 \%$. Pada siklus III terjadi peningkatan nilai rata-rata hasil belajar peserta didik menjadi 81 dengan persentase ketuntasan belajar klasikal sebesar $91 \%$. Hasil belajar IPA sudah memenuhi indikator keberhasilan yaitu $\geq 85 \%$ peserta didik kelas $\mathrm{VI}$ mengalami ketuntasan belajar dengan nilai diatas KKM dengan predikat Cukup (C). Dengan demikian maka hipotesis tindakan telah terbukti bahwa model Blended Learning menggunakan media audio visual dapat meningkatkan kualitas pembelajaran yang terdiri dari keterampilan guru, aktivitas peserta didik dan hasil belajar Tema Globalisasi muatan IImu Pengetahuan Alam di kelas VI SD Negeri 1 Magelung Kecamatan Kaliwungu Selatan.

\section{DAFTAR PUSTAKA}

BSNP. 2006. Standar Isi IImu Pengetahuan Alam untuk SD/MI. Jakarta : Depdiknas.

IPA. Jakarta: Depdiknas Badan Penelitian dan Pengembangan Pusat Kurikulum. Hasil

Belajar Peserta didik. Jurnal Universitas Pendidikan Indonesia. Vol. 2 (7):52-58.

Rusman. 2012. Model-Model Pembelajaran Mengembangkan Profesionalisme Guru. Jakarta: Raja Grafindo Persada.

Sardiman. 2011. Interaksi dan Motivasi Belajar Mengajar. Jakarta: Raja Grafindo Persada.

Susanto, Ahmad. 2013. Teori Belajar dan Pembelajaran. Jakarta: Kencana Prenadamedia Grup.

Suyono dan Hariyanto. 2014. Belajar dan Pembelajaran. Bandung: Remaja Rosdakarya.

Sutrisno, Leo dkk. 2007. Pengembangan Pembelajaran IPA SD. Jakarta: Direktorat Jendral Pendidikan Tinggi Departemen Pendidikan Nasional.

Trianto. 2011. Model-Model Pembelajaran Inovatif Berorientasi Konstruktivistik. Jakarta: Prestasi Pustaka. 